\title{
A New Screening Method for C-P Compound Producing Organisms by the Use of Phosphoenolpyruvate Phosphomutase
}

\author{
Hideo Nakashita, Akira Shimazu and Haruo Seto \\ Institute of Applied Microbiology, The University of Tokyo, \\ Bunkyo-ku, Tokyo 113, Japan \\ Received May 16, 1991
}

\begin{abstract}
Phosphoenolpyruvate phosphomutase (PEPPM) catalyzes the C-P bond forming reaction by intramolecular rearrangement of phosphoenolpyruvate to phosphonopyruvate, and shows stronger activity in catalyzing the reverse reaction than the forward reaction. By exploiting the activity of PEPPM to catalyze the reverse reaction, 81 strains were screened as possible C-P compound producing microorganisms from 230 soil samples. Two of these strains, B-1 and L-b, were found to produce C-P compounds by ${ }^{31}$ P-NMR spectral analysis of their broth filtrates. The activity of PEPPM was detected in the cell extracts of these two strains. The strain B-1 was identified as Pseudomonas gladioli, and hydroxyethylphosphonic acid (HEP) was isolated from the broth filtrate of this strain as a C-P compound.
\end{abstract}

Since the first discovery of the C-P compound 2-aminoethylphosphonic acid, ${ }^{1)}$ various metabolites with a C-P bond have been isolated and their physiological activities investigated. Extensive studies on their unique C-P bond formation mechanisms indicated that the first step of the biosynthetic pathway of C-P compounds is the intramolecular rearrangement of phosphoenolpyruvate (PEP) to phosphonopyruvate (PnPy) ${ }^{2)}$ (Fig. 1).

Recently phosphoenolpyruvate phosphomutase (PEPPM) catalyzing the C-P bond forming reaction was purified from Tetrahymena pyriformis $^{3)}$ and Streptomyces hygroscopicus, ${ }^{4)}$ and subsequently and surprisingly, the enzyme turned out to show stronger activity in catalyzing the reverse reaction, i.e., cleaving the $\mathrm{C}-\mathrm{P}$ bond to give PEP, than the $\mathrm{C}-\mathrm{P}$ bond

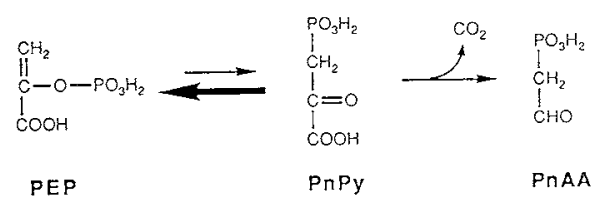

Fig. 1. Proposed Biosynthetic Pathway of C-P Bond Formation.

PEP, phosphoenolpyruvate; PnPy, phosphonopyruvate; PnAA, phosphonoacetaldehyde. formation. Although several studies on the mechanism of this reaction using PEPPM from Tetrahymena ${ }^{5)}$ were reported, the detailed mechanism is still unclear. While this reaction seems to be common to all of the C-P compound producing organisms, there is little biochemical evidence for generalization. To identify the detailed mechanism of C-P bond formation and the significance of C-P compounds in living systems, other organisms producing $\mathrm{C}-\mathrm{P}$ compounds need to be investigated.

To isolate such microorganisms capable of forming the C-P bond from soil samples, we used the strong activity of PEPPM to catalyze the reverse reaction. Thus, microorganisms that can produce C-P compounds are expected to be able to use PnPy as a sole phosphorus source by converting it into PEP by the reverse reaction. In addition to $\mathrm{PEPPM}, \mathrm{C}-\mathrm{P}$ cleaving enzymes such as phosphonatase ${ }^{6)}$ and C-P lyase $^{7)}$ are known to exist; therefore, microorganisms capable of growing in a medium containing phosphonoalanine (PnAla; 2-amino-3-phosphonopropionic acid), a biological equivalent of $\mathrm{PnPy}$, as a sole phosphorus source and capable of producing PEP, could be expected to have PEPPM and produce C-P com- 
pounds.

To select microorganisms truly capable of producing C-P compounds from soil isolates that were obtained as being able to use PnPy as a sole phosphorus source, we used ${ }^{31} \mathrm{P}$ NMR spectroscopy for detecting the accumulation of C-P compounds in the fermentation broth. ${ }^{31} \mathrm{P}-\mathrm{NMR}$ spectroscopy is an effective method for analyzing phosphorous compounds and is widely used in cell physiology and plant physiology. In the ${ }^{31} \mathrm{P}-\mathrm{NMR}$ spectra the signals due to phosphoric acid and phosphate esters are observed at around $0 \mathrm{ppm}$, while those of the phosphorus in C-P compounds are detected at about 45-10 ppm. Therefore, C-P compounds in fermentation broth could be detected effectively with ${ }^{31} \mathrm{P}-\mathrm{NMR}$ spectroscopy. Here we describe the screening of microorganisms that produce the C-P compounds and their PEPPM activity.

\section{Materials and Methods}

Screening of microorganisms. To facilitate isolation of C-P compound producing organisms, enrichment culture was done in a synthetic medium containing PnAla as a sole phosphorus source. Soil samples $(0.5 \mathrm{~g})$ were separately suspended in $5 \mathrm{ml}$ of $0.9 \% \mathrm{NaCl}$, and samples of the supernatant $(100 \mu 1)$ were transferred into $50-\mathrm{ml}$ culture tubes, each containing $10 \mathrm{ml}$ of $\mathrm{M}(\mathrm{C}-\mathrm{P})$ medium. $\mathrm{M}(\mathrm{C}-\mathrm{P})$ medium contained $1 \%$ glucose, $0.05 \%$ L-asparagine, $0.01 \%$ PnAla, $0.02 \% \mathrm{MgSO}_{4} \cdot 7 \mathrm{H}_{2} \mathrm{O}$, and $0.001 \% \mathrm{FeSO}_{4} \cdot 7 \mathrm{H}_{2} \mathrm{O}$ (pH 7.5). After incubation for 3 or 4 days at $27^{\circ} \mathrm{C}$ under aerobic condition, $100 \mu \mathrm{l}$ of the culture was transferred into a new medium of the same composition and cultured continuously. This procedure was repeated three times to minimize the carrying over of phosphorus from soil samples. Finally samples of the cultures $(200 \mu \mathrm{l})$ were spread on agar plates consisting or M(C-P) medium, and incubated at $27^{\circ} \mathrm{C}$ for several days to isolate single colonies.

Assay for ability to produce C-P compounds. Isolated strains were separately inoculated into $500-\mathrm{ml}$ Erlenmeyer flasks, each containing $100 \mathrm{ml}$ of $\mathrm{M}$ medium, and incubated at $27^{\circ} \mathrm{C}$ for 3 days. $\mathrm{M}$ medium contained $1 \%$ glucose, $0.05 \%$ L-asparagine, $0.05 \% \mathrm{~K}_{2} \mathrm{HPO}_{4}, 0.02 \% \mathrm{MgSO}_{4}$. $7 \mathrm{H}_{2} \mathrm{O}$, and $0.001 \% \mathrm{FeSO}_{4} \cdot 7 \mathrm{H}_{2} \mathrm{O}$. The broth filtrate was concentrated by evaporation to about $10 \mathrm{ml}$, and analyzed by ${ }^{31} \mathrm{P}-\mathrm{NMR}$ spectroscopy under basic conditions $(\mathrm{pH}$ 11) adjusted by adding NaOH. ${ }^{31} \mathrm{P}-\mathrm{NMR}$ measurements were done with a JEOL GSX500 NMR spectrometer operating at $202.35 \mathrm{MHz}$. The probehead was a JEOL $10-\mathrm{mm}$ multinuclear unit tuned for the ${ }^{31} \mathrm{P}$ nucleus. Chemical shift values are reported relative to $85 \% \mathrm{H}_{3} \mathrm{PO}_{4}$. All NMR measurements were done at $25^{\circ} \mathrm{C}$.

Enzyme assay. Microorganisms were cultured in $500 \mathrm{ml}$ Erlenmeyer flasks containing $100 \mathrm{ml}$ of the $\mathrm{M}$ medium for 3 or 4 days and cell extracts were prepared by sonication of cells suspended in $50 \mathrm{~mm}$ Tris- $\mathrm{HCl}$ buffer $(\mathrm{pH} 7.5)$. The reverse reaction activity of PEPPM was assayed with a system consisting of $50 \mathrm{mM}$ Tris $-\mathrm{HCl}(\mathrm{pH}$ 7.5), 0.27 mM PnPy, 0.15 mM NADH, 0.72 mM ADP, $5 \mathrm{~mm}$ $\mathrm{MgSO}_{4} \cdot 7 \mathrm{H}_{2} \mathrm{O}, 5 \mathrm{U} / \mathrm{ml}$ lactate dehydrogenase and $5 \mathrm{U} / \mathrm{ml}$ pyruvate dehydrogenase. The reaction was started by the addition of the cell extract, and then the decrease in adsorbance at $340 \mathrm{~nm}$ was recorded at $30^{\circ} \mathrm{C}$. The activity was measured by the difference of the decrease in absorbance between the presence and the absence of PnPy. One unit of PEPPM activity was defined as the amount converting $1.0 \mu \mathrm{mol}$ of PnPy to PEP per minute. Protein was measured by the method of Lowry et al. ${ }^{8)}$

Isolation of C-P compounds. During isolation procedures, C-P compounds were followed by ${ }^{31} \mathrm{P}-\mathrm{NMR}$ spectroscopy. Strain B-1 was inoculated into $500 \mathrm{ml}$ Erlenmeyer flasks containing $100 \mathrm{ml}$ of $\mathrm{M}$ medium, and incubated at $27^{\circ} \mathrm{C}$ for 4 days. Broth filtrate (20 liters) was treated with activated carbon and the supernatant was adsorbed on a Dowex 1 column $\left(\mathrm{Cl}^{-}\right.$form, $\left.65 \times 850 \mathrm{~mm}\right)$. After washing with water, the column was eluted with $0.1 \mathrm{M} \mathrm{NaCl}$, and the eluate was passed through a Dowex 50 column $\left(\mathrm{H}^{+}\right.$form, $\left.46 \times 500 \mathrm{~mm}\right)$ and the column was washed successively with water. Effluent and washing fractions containing C-P compounds were adjusted to $\mathrm{pH} 10$ with conc. $\mathrm{NH}_{4} \mathrm{OH}$ and were adsorbed on a QAE-Sephadex A-25 column ( $\mathrm{Cl}^{-}$form, $38 \times 500 \mathrm{~mm}$ ). After it was washing with water and $0.09 \mathrm{M} \mathrm{NaCl}$, the column was eluted with $0.14 \mathrm{M} \mathrm{NaCl}$. Fractions containing C-P compounds were combined and concentrated, and then chromatographed on a Sephadex G-25 column chromatography $(20 \times 1400 \mathrm{~mm})$ developed with water. The combined fraction containing C-P compounds was dried by evaporation, and then the dry residue was put on a cellulose column $(20 \times 500 \mathrm{~mm})$ equilibrated with $\mathrm{EtOH}-$ $\mathrm{NH}_{4} \mathrm{OH}-\mathrm{H}_{2} \mathrm{O}=8: 1: 2$. Development with the same solvent mixture gave $0.5 \mathrm{mg}$ of the ammonium salt of the C-P compound.

\section{Results and Discussion}

\section{C-P compound producing strains}

From 230 soil samples were obtained 81 strains capable of using PnAla as a sole phosphorus source. ${ }^{31} \mathrm{P}-\mathrm{NMR}$ spectra of broth filtrates of these isolated strains cultivated in $M$ medium had a signal at about $18.5 \mathrm{ppm}$ 


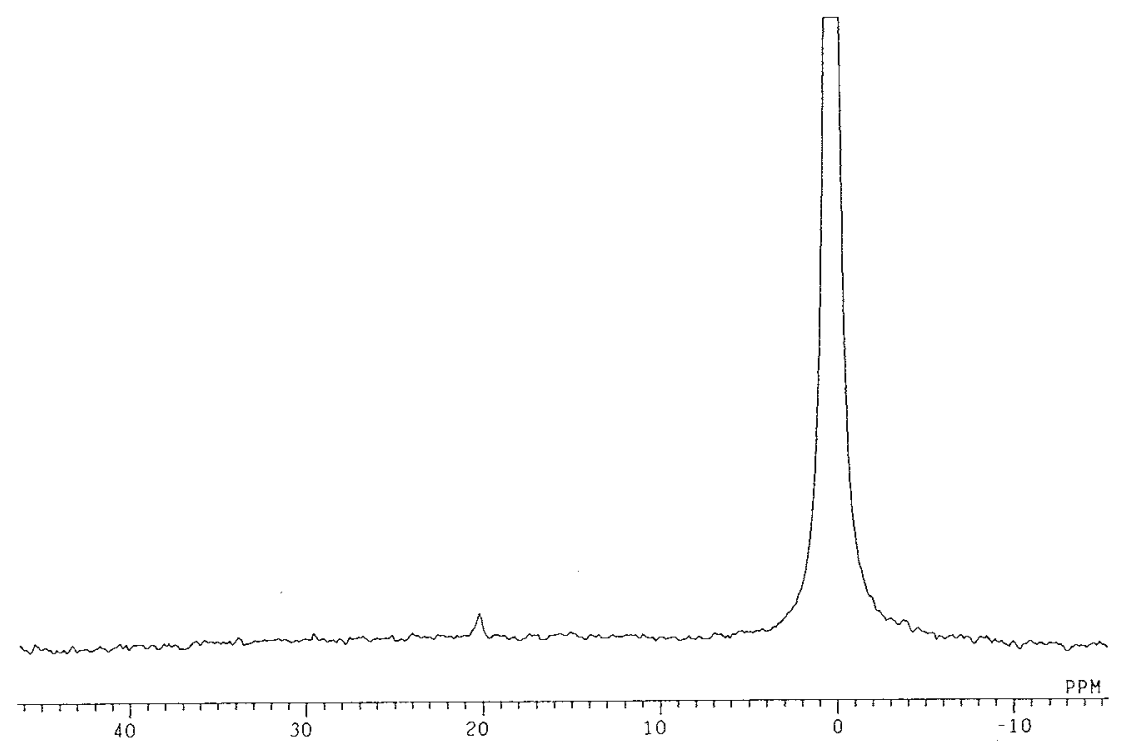

Fig. 2. ${ }^{31}$ P-NMR Spectrum of Broth Filtrate of Strain B-1.

The broth filtrate of $\mathrm{B}-1$ was concentrated to about $1 / 10$, adjusted to $\mathrm{pH} 11$ with $\mathrm{NaOH}$. A large signal at about $2-3 \mathrm{ppm}(0 \mathrm{ppm}$ at $\mathrm{pH} 7)$ was assigned to phosphate and a small signal at $20 \mathrm{ppm}$ was phosphonate.

assignable to phosphonic acid in the broth filtrate of two strains, B-1 and L-b, suggesting accumulation of a C-P compound in the fermentation broth of these two strains (Fig. 2).

In addition to the production of a C-P compound by these strains, their abilities to use PnAla as a sole phosphorus source and to cleave the C-P bond were also examined by ${ }^{31}$ P-NMR measurements. NMR analysis of the fermentation broth cultured in $\mathrm{M}(\mathrm{C}-\mathrm{P})$ medium showed one signal at about 0 ppm in addition to the signal of PnAla, indicating the cleavage of the C-P bond of PnAla by these strains.

\section{Production of $C-P$ compounds by strain $B-I$ and $L-b$}

Since the phosphorous chemical shifts of C-P compounds in L-b and B-1 were identical, both strains were assumed to produce the same C-P compound. Since the amount of the C-P compound produced by L-b was too small, the isolation of the C-P compound produced by strain $\mathrm{B}-1$ was done as described in $\mathrm{Ma}$ terials and Methods. The structure of the isolated compound was identified as follows.
In the ${ }^{1} \mathrm{H}-\mathrm{NMR}$ spectrum taken in $\mathrm{D}_{2} \mathrm{O}$, two methylene signals ( $\delta_{\mathrm{H}} \quad 3.75$ and 1.73 ) were coupled with each other $(J=8.2 \mathrm{~Hz})$ and phosphorus $\left({ }^{2} J_{\mathrm{P}-\mathrm{H}}=7.1 \mathrm{~Hz},{ }^{3} J_{\mathrm{P}-\mathrm{H}}=16.5 \mathrm{~Hz}\right)$ indicating the presence of a $\mathrm{P}-\mathrm{CH}_{2}-\mathrm{CH}_{2}$ unit. The downfield shift of one of the methylene signals suggests its linkage to a hydroxyl group. The ${ }^{13} \mathrm{C}-\mathrm{NMR}$ spectrum of this compound showed a very characteristic doublet signal at $\delta_{\mathrm{C}} 32.5\left(J_{\mathrm{C}-\mathrm{P}}=125 \mathrm{~Hz}\right)$ due to a $\mathrm{C}-\mathrm{P}$ bond.

Based on these NMR spectral analyses and comparison with a standard sample, the structure of the isolated compound was identified as hydroxyethylphosphonic acid (HEP). This compound had been obtained from the broth filtrate of a blocked mutant of a bialaphosproducing organism ${ }^{9)}$ and was known as a biosynthetic intermediate of fosfomycin. ${ }^{10}$ ) The ability of C-P bond formation of strain B-1 was thus confirmed by HEP production.

The identification of this strain was done from Bergey's Manual of Systematic Bacteriology (Vol. 1). The strain B-1 was isolated from a soil sample collected in Hongo, Bunkyo-ku, Tokyo Prefecture, Japan. This strain is a Gram-negative and strictly aerobic rod, motile 
Table I. Morphological and Physiological Properties of Strain B-1

\begin{tabular}{|c|c|}
\hline Morphology & Rod \\
\hline Length & $1.1-3.5 \mu \mathrm{m}$ \\
\hline Width & $0.4-0.6 \mu \mathrm{m}$ \\
\hline Colony morphology & , smooth surface \\
\hline Pigmentation & - \\
\hline Number of flagella & $>1$ \\
\hline Mobility & + \\
\hline Gram stain & Negative \\
\hline Endospore formation & - \\
\hline Oxidase & + \\
\hline Catalase & + \\
\hline Urease & - \\
\hline Lipase & + \\
\hline OF-test & Oxidative \\
\hline$\beta$-Galactosidase & + \\
\hline Denitrification & - \\
\hline Arginine dihydrolase & - \\
\hline Nitrate reduction & + \\
\hline Slime production from sucrose & + \\
\hline Poly- $\beta$-hydroxybutyrate accumulation & + \\
\hline Gelatin liquefaction & + \\
\hline Protocatechuate, ortho cleavage & + \\
\hline Utilization of ammonium & + \\
\hline Nitrate & + \\
\hline Adonitol & + \\
\hline L-Rhamnose & - \\
\hline D-Ribose & + \\
\hline D-Xylose & + \\
\hline D-Glucose & + \\
\hline 2,3-Butyleneglycol & - \\
\hline D- $(-)$-Tartrate & + \\
\hline Mesaconate & + \\
\hline Levulinate & - \\
\hline$m$-Hydroxybenzoate & - \\
\hline Tryptamine & - \\
\hline$\alpha$-Amylamine & - \\
\hline Citraconate & + \\
\hline Citrate & + \\
\hline
\end{tabular}

by polar flagella, metabolizes glucose oxidatively, and is positive for catalase and oxidase. This strain accumulated poly- $\beta$-hydroxybutyrate as a carbon reserve material, and is negative for dihydrolase and denitrification (Table I). From these characteristics and the carbon utilization, this strain was identified as $P_{s e u-}$ domonas gladioli and designated $P$. gladioli B-1.

PEPPM activity of Pseudomonas gladioli $B-1$

Since $P$. gladioli $\mathrm{B}-1$ produced HEP, this strain was reasonably assumed to have PEPPM
Table II. PEPPM Activity in Cell Extract of P. gladioli $\mathrm{B}-1$

\begin{tabular}{ccccc}
\hline \multirow{2}{*}{ Cell extract } & \multicolumn{2}{c}{$\begin{array}{c}\text { Consumption of } \\
\mathrm{NADH}\left(A_{340} / \mathrm{min}\right)\end{array}$} & $\begin{array}{c}\text { Specific activity } \\
\left(10^{-3} \text { Unit/mg }\right. \\
\text { protein })\end{array}$ \\
\cline { 3 - 4 } & & $+\mathrm{PnPy}$ & $-\mathrm{PnPy}$ & \\
\hline $\mathrm{I}$ & $-\mathrm{PK}$ & 0.0345 & 0.0320 & - \\
& $+\mathrm{PK}$ & 0.0420 & 0.0323 & 7.25 \\
2 & & 0.1070 & 0.0488 & 346.5 \\
\hline
\end{tabular}

The cell extract ( 1 , cultivated in flasks, $4.30 \mathrm{mg}$ protein $/ \mathrm{ml}, 50 \mu \mathrm{l} ; 2$, cultivated by jar fermentor, $1.35 \mathrm{mg}$ protein $/ \mathrm{ml}, 50 \mu \mathrm{l}$ ) was added to $950 \mu \mathrm{l}$ of the assay mixture.

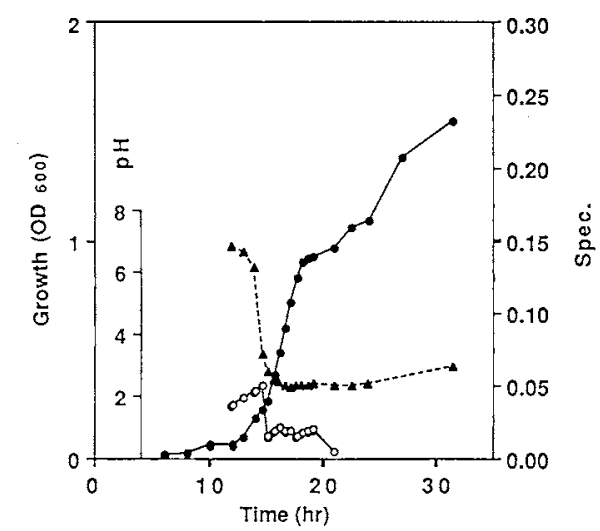

Fig. 3. Course of Cultivation and PEPPM Activity of $P$. gladioli B-1.

$-\longrightarrow$, growth; --- $\mathbf{A}---$ pH; $-\mathrm{O}-$, specific activity of PEPPM $\left(10^{-3}\right.$ Unit/mg protein).

activity. This enzymatic activity in the exract of $P$. gladioli $\mathrm{B}-1$ cells grown in $\mathrm{M}$ medium was evaluated by measuring the amount of PEP spectrophotometrically, which was formed from PnPy by the reverse reaction, by ADP/pyruvate kinase-NADH/lactate dehydrogenase coupled system. ${ }^{11)}$ The absorbance at $340 \mathrm{~nm}$ of the reaction mixture containing PnPy decreased faster than that without the substrate PnPy (Table II). Since the PEPPM activity of $P$. gladioli B-1 was very weak, the relationship between the enzyme activity and the cell growth was examined by cultivating strain B-1 in $\mathrm{M}$ medium by a jar fermentor. Under these growing conditions, about 15 hr after the start of the cultivation the enzyme activity suddenly appeared and gradu- 
ally decreased to an undetectable level in about an hour (Fig. 3). Attempts to detect the forward reaction catalyzed by PEPPM were unsuccessful based on the method using NADH/malate dehydrogenase. ${ }^{4)}$ This result supports the observation that the forward reaction is weaker than the reverse reaction, in agreement with the nature of PEPPM from $S$. hygroscopicus. Although PEPPM was purified from Tetrahymena pyriformis and S. hygroscopicus, this is the first time of the detection of PEPPM activity in Gram-negative bacteria.

The PEPPM activity of strain L-b was undetectable when culture was done in Erlenmeyer flasks, but a little was observed when cultivated in a jar fermentor in the same way as strain B-1. Therefore, strain L-b is also believed to be a C-P compound producing microorganism. Thus we have succeded in isolating two microorganisms producing $\mathrm{C}-\mathrm{P}$ compounds from soil samples.

If other phosphonic acids such as 2-aminoethylphosphonic acid (AEP) or phosphonoacetic acid (PnAc) were used as a sole phosphorus source, most of the isolated microorganisms would have shown only either phosphonatase or C-P lyase activity, and could only cleave $\mathrm{C}-\mathrm{P}$ bonds but not form $\mathrm{C}-\mathrm{P}$ bonds. Therefore, the screening method exploiting the nature of PEPPM, using PnAla as a sole source of phosphorus turns out to be very effective in obtaining new microorganisms capable of producing C-P compounds. By application of this method, not only the promotion of the study of PEPPM and mechanism of C-P bond formation but also the discovery of new natural C-P compounds with biological activities, will become possible.

In spite of the formation of C-P compounds, the activity of the forward reaction of PEPPM is weaker than that of the opposite reaction. It may be due to the energetic stability of each compound related to this reaction in the living system. ${ }^{5}$ So in the living system there is a mechanism of stabilizing C-P bonds to produce C-P compounds. We propose that in the course of production of C-P compounds, the next reaction to $\mathrm{C}-\mathrm{P}$ bond formation by PEPPM, perhaps PnPy to phosphonoacetaldehyde $(\text { PnAA })^{12)}$ (Fig. 1), occurred successively remove the reaction product (PnPy) to drive the reaction equilibrium irreversibly in favor of the formation of the C-P bond. Although this reaction has not been detected, the organisms which were obtained by our screening in this report will be useful in studying those mechanisms.

\section{References}

1) M. Horiguchi and M. Kandatsu, Nature, 184, 901 (1959).

2) W. A. Warren, Biochim. Biophys. Acta, 156, 340 (1968)

3) H. M. Seidal, S. Freeman, H. Seto and J. R. Knowles, Nature, 335, 457 (1988).

4) T. Hidaka, M. Mori, S. Imai, O. Hara, K. Nagaoka and H. Seto, J. Antibiot., 42, 491 (1989).

5) E. Bowman, M. McQueney, R. J. Barry and D. Dunaway-Mariano, J. Am. Chem. Soc., 110, 5575 (1988).

6) J. M. La Nauze, H. Rosenberg and D. C. Shaw, Biochim. Biophys. Acta, 212, 332 (1970).

7) K. Murata, N. Higashi and A. Kimura, J. Bacteriol., 171, 4504 (1989).

8) O. H. Lowry, N. J. Rosebrough, A. L. Farr and R. J. Randall, J. Biol. Chem., 193, 265 (1951).

9) S. Imai, H. Seto, T. Sasaki, T. Tsuruoka, H. Ogawa, A. Satoh, S. Inouye, T. Niida and N. Otake, $J$. Antibiot., 37, 1505 (1984)

10) S. Imai, H. Seto, H. Ogawa, A. Satoh and N. Otake, Agric. Biol. Chem., 49, 873 (1985).

11) L. A. Bentle and H. A. Lardy, J. Biol. Chem., 251, 2916 (1976).

12) M. Horiguchi, "Metabolism of Phosphonic Acid and Phosphinic Acid," in "Biochemistry of Natural C-P Compouds," ed. by T. Hori et al., Japanese Asociation for Research on the Biochemistry of C-P Compounds, Kyoto, 1984, pp. 88-103. 